\title{
CONTEMPORARY ISSUES IN ECONOMICS ENGINEERING: ECONOMIC GROWTH, DYNAMIC MANAGEMENT, AND TECHNOLOGICAL BREAKTHROUGHS
}

\author{
Borisas MELNIKAS \\ Department of Economics Engineering, Vilnius Gediminas Technical University, \\ Saulètekio al. 11, Vilnius, Lithuania \\ E-mail:melnikas@vgtu.lt
}

\begin{abstract}
Purpose - to prepare, disseminate and implement the new concept of economics engineering, the essence of which is an integrated approach to the problems of economic growth, innovation activities, technological progress, and breakthroughs.

Research methodology - systematic analysis and synthesis of various scientific ideas and approaches, formulation and analysis of new insights.

Findings - a new concept of economics engineering is prepared. This concept provides an integrated approach to the solution of the problems of economic growth, innovation activities, technological progress, and breakthroughs, as well as of the application of dynamic management tools. The implementation of this concept in the practice of the economic activities and research creates various preconditions for anticipation and realization of new opportunities for economic development and technological breakthroughs under contemporary conditions of globalization, European integration and the creation of knowledge-based society and knowledge economy.
\end{abstract}

Research limitations - the proposed concept is limited to the cases of the macroeconomic analysis and preparation of the strategic economic decisions.

Practical implications - the proposed concept is usable in various cases of economic policy decisions making.

Originality/Value - the new insights and perspective ideas provided for the priorities of the economics engineering science and of the application of the dynamic management tools, are described and analyzed. Orientation to these insights and ideas highlights new significant trends in the scientific research of economic profile.

Keywords: economics engineering, economic growth, dynamic management, technological advance, innovation, synergy.

JEL Classification: A10, F01, F39, Q39.

Conference topic: Contemporary Issues in Economics Engineering.

\section{Introduction}

The economics engineering could be appreciated as a new and a very significant field in the contemporary science of economics. Under these circumstances, it is relevant to discuss and identify the essentials and key concepts and provisions of economic engineering, as well as to define, explore and investigate those ideas, development tendencies, and directions, that could be understood as of particular significant and promising.

The economics engineering could be defined as an exceptionally new and significant area of the science of economics, of the scientific research on economic development, as well as of the practical activities in various fields and sectors of the contemporary economy. Obviously that the science of economics engineering is characterized by certain exceptional features, including orientations to economic growth, technological advance, and breakthroughs, as well as to various social innovations: in general, orientation towards economic growth and qualitative changes specific to the life of the contemporary society can be seen as an exceptionally important characteristic of the science of economics engineering and of the modern economics in general.

The problems of economic growth, technological advancement, and breakthroughs, as well as the problems of activation of social innovations, can be considered as the most important problems of the science of economics engineering. The solving these problems requires adequate management models and tools: this leads to the conclusion that

(C) 2019 Author. Published by VGTU Press. This is an open-access article distributed under the terms of the Creative Commons Attribution (http://creativecommons.org/licenses/by/4.0/) License, which permits unrestricted use, distribution, and reproduction in any medium, provi-ded the original author and source are credited. 

and technological breakthroughs

the purposeful application of the ideas and tools of the so-called dynamic management is to be regarded as a very important precondition for successful solving of these problems. The analysis of phenomena and the practical solving of various problems in the main fields of economics engineering could be defined as inseparable from the studies and research on the dynamic management and its applications.

Various opportunities for targeted and successful solving of the problems of economics engineering are based on appropriate scientific knowledge and cognition: an important priority of this scientific cognition - the use and application of the ideas and tools of the dynamic management, in particular to successfully solve the problems of the economic growth, as well as the problems of the social and technological progress and breakthroughs.

The lack of complex scientific knowledge and cognition in the area of the application of the ideas and tools of dynamic management to stimulate economic growth and innovations and to accelerate the social and technological progress and breakthroughs can be understood as a priority problem of practical activities and of the scientific research on economics engineering. Do not doubt that the efforts to solve this problem must be considered as a very topical: the results of the scientific research in this field can be very innovative, they can enrich understanding about contemporary economic life and broaden the knowledge about economics engineering.

So, scientific research on economics engineering, including on the application of the ideas and tools of dynamic management to stimulate economic growth and innovations and to accelerate the social and technological progress and breakthroughs, could be unequivocally appreciated as a very necessary and useful.

The essence of such scientific research can be described by answering several questions.

The answer to the question "What do we know?" may be approximately this: it can be said that a very large amount of theoretical and practical knowledge in the field of the processes of economic growth, innovations, and acceleration of the social and technological progress and breakthroughs has been accumulated in the contemporary economic science, but this knowledge is often very fragmented, is not properly structured, this mass of knowledge does not highlight the essential prerequisites.

The answer to the question "What do we not know?" may be approximately this: it can be said that the essential theoretical principles, phenomena and theoretical generalizations describing various circumstances and the processes of economic growth, innovation activities and the main tendencies of the social and technological progress and breakthroughs are not properly targeted to the needs of contemporary society and its development and modernization.

The answer to the question "What and why should we know?" may be approximately this: it can be said that the deep and broad analysis of new ideas for the activation of the processes of economic growth and innovation, as well as promotion of the social and technological changes and breakthroughs, is very necessary. This analysis should be oriented to the contemporary challenges and needs of globalization, European integration and creation of knowledgebased society and knowledge economy, as well as to the needs to create and develop the theoretical basis for the creation and further modernization of various support systems needed for purposeful improvement of management and governance processes in all spheres of the social and economic life of contemporary society.

The main scientific problem investigated in this publication, is that the main current theoretical approaches to various development processes and phenomena that are being studied and investigated in the modern science of economics and economics engineering, as well as in the science of management, are not adequate for the needs of the economic growth and innovation activities and for the challenges of the social and technological progress and breakthroughs. The essence of this problem is also that there is in the practice a lack of the appropriate theoretical models, solutions, and concepts that allow the development and use of effective support systems for the application of the ideas and tools of dynamic management to stimulate economic growth and innovations and to accelerate the social and technological progress and breakthroughs.

The main hypothesis focused on the solution of this problem can be formulated with two statements: a) the processes of economic growth, innovation activities and acceleration of the social and technological progress and breakthroughs could be investigated and identified as an economic phenomenon reflecting fundamental qualitative changes in all spheres of the life of society; b) the key conditions and possibilities for the purposeful activation of these processes could be comprehensively defined, especially - taking into account contemporary factors of globalization, European integration and of the knowledge-based society and knowledge economy creation.

The object of the research is twofold: a) the economics engineering as a new promising field of the scientific cognition and research, as well as a relevant field of various practical activities; b) the processes of economic growth, innovation activities and acceleration of the technological progress and breakthroughs.

Tasks of the research:

- to explore the role and importance of the processes of fundamental qualitative changes and of the search and use of various forms of synergy and synergetic effects, especially - in the context of the needs to activate economic growth, innovations and the social and technological progress and breakthroughs; ties of the research on economics engineering and dynamic management in general;

- to describe the role and importance of the complex scientific research on economics engineering and dynamic management in general, to determine the main priorities of further research.

The methodology of the research is based on the traditional approaches to theoretical research and scientific cognition. Various ideas of the complexity of scientific cognition, of the analysis of quantitative and qualitative 
changes, as well as of the use of different methods and models of investigation and complex analysis of the processes of social and economic development are being implemented in the course of the research. The results of scientific research are presented in this publication. The scientific novelty of these results can be described as follows: the new insights and analytical materials reflect some new ideas that can be used in the academic studies and scientific research on the processes of economic growth, innovation activities and of the acceleration of the social and technological progress and breakthroughs. The practical value is that the results of the research can be used as the theoretical basis for the creation and further development of various support systems needed to activate the economic growth and innovation activities and to accelerate the social and technological progress and breakthroughs.

\section{The economics engineering: fundamental qualitative changes, synergetic effects, the key priorities}

Economic engineering, its essence, problems, and priorities can be described by the statements published in the previous publications (Melnikas, 2013, 2018). It can be said that “...the economics engineering is recently perceived as an essential part of the traditional science of economics and as a viable and prospective field of fundamental and applied scientific research of economic profile. By the way, the concept and definition of economics engineering are rather new, it is still not defined unambiguously, definitively and indisputable. It is also evident that economics engineering and the research activities and academic studies devoted to it, as a relatively new field, have become more and more widespread in recent times..." (Melnikas, 2018).

The main theoretical attitudes and the basic ideas to develop the science of economics engineering and to solve the most important problems of economic life are widely considered in many significant scientific works (Collier, 2018; Haskel \& Westlake, 2018; Newnan, Lavelle, \& Eschenbach, 2017; Steger, 2017; Loy \& Aageson, 2018). In general, the concept and definition of economics engineering can be based on a variety of different ideas.

One of the possible versions of such a concept or definition is that the understanding of the essence of economics engineering is based on the idea that the word "engineering" in the whole means many orientations: to the knowledge about the structure of a particular object, phenomenon or system, as well as to the processes of exploring, designing or creation and development of the structure of a particular object or system (Buede \& Miller, 2016).

There is no doubt that "...the concept and definition of the economics engineering can be defined and described as expressing and representing the scientific and practical activities oriented to the knowledge about the structures of a various economic systems and objects of economic activities, about the trends and structures of the processes of economic development, as well as to the processes of exploring, designing or creation and development of new structures in various fields and systems of economic life. The essence of economics engineering, as of science, reflects the orientation to the dynamism of economic activities and the qualitative changes in economic life." (Melnikas, 2018).

By the way, the orientation to the dynamism of economic activities and qualitative changes in economic life, in general, can be described as a fundamental qualitative change in the economy. Such changes are always dynamic, their dynamism is characterized by a variety of forms. It should be noted that the definition of the fundamental qualitative changes usually reflects the changes in the content, logic, and structure of the various systems, as well as themselves, change processes in the context of the time: this suggests that the fundamental qualitative changes and orientations to these changes can be defined as the most important and exceptional feature of the science of economics engineering.

Thus, scientific research, academic studies, and practical activities in the field of economics engineering must be related to the analysis, initiation or implementation of fundamental qualitative changes. In cases where the current economic and other problems are analyzed and solved in the context of the ideas of the economics engineering science, the main decisions themselves have to be focused on the fundamental qualitative changes.

In turn, fundamental qualitative changes can be very diverse and can occur in different forms. The fundamental qualitative changes, that are attributable to the innovation activities and to the scientific and technological progress, as well as to the economic growth, can be considered as particularly important.

It is also necessary to emphasize that the processes of innovations, of the scientific and technological progress, of the economic growth, as well as various possibilities for activation and acceleration of these processes, must be examined and studied in the context of the contemporary challenges of globalization, European integration and the creation of a knowledge-based society. Scientific cognition and investigations in this area can also be considered as an important priority of the research on economics engineering.

Priority attention to the problems and processes of economic growth, innovation activities, technological advance and breakthroughs in the context of the challenges of globalization, European integration and the creation of a knowledge-based society is reflected in many fundamental research works (Castells, 2000-2004; Mody, 2018; Collier, 2018; Harary, 2016, 2018; Hunt, 2000; Johnson \& Turner, 2010; Marshall, 2018; Neelankavil, 2015; Steger 2017; Melnikas Reichelt, 2004.).

The ideas presented in these works can be considered as the basis for initiating and implementing new approaches to the economics engineering in general, as well as to successful solutions of the scientific and practical problems related to the fundamental qualitative changes in various areas of social and economic life. It is necessary to take into account various forecasts and insights that are oriented towards the long-term perspective (Die Welt im Jahr 2035..., 2017). 

and technological breakthroughs

In examining and assessing the prospects for the development processes in various areas of the social and economic life, and in particular, taking into account the needs and priorities of various fundamental qualitative changes, it may be recommended to apply the so-called universal principle of the creation of a "new quality". As it is stated in previous research works and publications, "... universal principle of the creation of a "new quality" reflects the fundamental ideas of synergetics and of the processes of the search and use of synergetic effects." (Melnikas, 2011, 2013, 2014, 2018).

Previous publications show, that "...the universal principle of the creation of a "new quality" can be seen as the most important principle to be applied in the scientific research, academic studies and practical activities in the field of economics engineering. This principle shows that the new quality always develops by the amalgamation when elements of different origin that never had belonged to the same system collide. This principle expresses the idea of the developing and using the synergetic effects, and demonstrates that qualitative transformations always require actions and means necessary to join elements of different origin to the common system." (Melnikas, 2011, 2013, 2014, 2018).

Previous publications show that there is a variety of the processes of connection or join of different elements. Usually can be identified two types of such processes: processes of integration and processes of synthesis. The combination of these processes makes it possible to initiate and get the appropriate synergetic effects, in other words - a "new quality" (Melnikas, 2011, 2013, 2014, 2018). Summarizing the statements made, it can be noted that the principle of the creation of a "new quality" can be considered as particularly important in the scientific research on economic engineering and in the relevant practical activities: the practical application of this principle creates various real preconditions for the purposeful activation of economic growth, innovations and technological advances and breakthroughs.

\section{Dynamic management: key ideas and their application in the context of the needs to activate the processes of economic growth and technological breakthroughs}

Obviously, many of the problems of economics engineering are specific, so solving these problems requires the use of adequate ideas and tools of governance and management: it can be noted that the relevant scientific and practical knowledge about the ideas and the tools of governance and management, that can be used to solve many problems of economics engineering, can be defined as an important part of the system of knowledge about the economics engineering in general (Melnikas, 2011; Chlivickas \& Melnikas, 2016; Melnikas et al., 2018).

Various opportunities for targeted and successful solving of the problems of economics engineering are based on appropriate scientific knowledge and cognition, including - on the scientific cognition of application of the ideas and tools of the so-called dynamic management, as well as of the relation of these tools and ideas to the solution of the contemporary problems of economic growth, social and technological advance, qualitative changes in general, innovations and breakthroughs.

It can be said that the lack of complex scientific knowledge and cognition in the area of the application of the ideas and tools of dynamic management to stimulate economic growth and innovations and to accelerate the social and technological progress and breakthroughs can be understood as an essential problem of the science of economics engineering. It goes without saying that the scientific research focused on solving this problem must be considered as a very topical: the results of such research can be very innovative, they can enrich understanding about contemporary economic life and broaden the knowledge about economics engineering.

So, scientific research on the application of the ideas and tools of dynamic management to stimulate economic growth and innovations and to accelerate the social and technological progress and breakthroughs could be unequivocally appreciated as a very necessary and useful.

Dynamic management can also be described as a new and highly promising area of scientific cognition and research, and as a very important field of practical activities. By the way, many scientific works in the field of modern management and contemporary decision-making theory can be considered as the theoretical basis for dynamic management and dissemination of its ideas (Endes, 2018; Aricly, 2008; Baron, 2007; Binmore, 2009; Teece, 2011; Buede \& Miller, 2016; In-Ho Kim 2008; Peterson, 2009; Inamori, 2013; Spetzler, Winter, \& Meyer, 2016).

Dynamic management in the most general case can be described as a kind of governance and management activities. Obviously that the modern governance and management activities need to be increasingly dynamic, with a tendency towards ever more rapid and intense changes and breakthroughs in all areas of life. It is noteworthy that the accelerating progress of science and technology, the increasing importance of creative activities and the general tendencies towards the dynamism and diverse changes and breakthroughs reflect the fundamental transformation of the traditional governance and management activities into the new qualitative state-of-the-art activities: it is obvious that the modern governance and management activities of a new type and new qualitative state can be defined and described as a dynamic management.

Considering that dynamic management must be directly related to those problems and processes of the social and economic development that are perceived as essential priorities in the economics engineering science, it can be said that the key feature of the dynamic management is the orientation towards the dynamism in general, including the orientation towards various fundamental qualitative changes. This statement shows that both dynamic management 
and economics engineering, as two different but complementary fields of science and practice, can be described by highlighting the commonality of the key features.

The needs for a deep scientific cognition and successful practical application of the ideas and tools of the dynamic management determines the necessity to define certain principles that should be taken into account in the most important cases of the dynamic management activities, especially in various cases of the initiation and dissemination of new ideas of dynamic management, as well as in various cases of the implementation of effective tools and instruments of the dynamic management. Among these principles are the following:

- the principle of dynamism, which expresses the fundamental view that dynamic management is by its nature oriented to the rapid and intense multidimensional changes and breakthroughs, especially to the various qualitative changes;

-the principle of humanistic attitudes and ethical and moral priorities, reflecting the needs and necessity to shift the processes of the changes and breakthroughs into the implementation of humanistic values and high ethical and moral norms and standards;

- the principle of coherence and sustainability, reflecting the view that the various processes of the changes and breakthroughs, as well as the governance and management solutions for such changes and breakthroughs, must be geared towards the coherence and sustainability both in the systems undergoing changes and breakthroughs and in the environment of such systems;

- the principle of rationality, efficiency and reasonableness, which expresses the needs for the responsible and reasoned initiation, development and implementation of the governance and management solutions oriented towards the progressive changes and breakthroughs, as well as which reflects the needs to increase efficiency of the changes and breakthroughs in all spheres of the social and economic life and development, in various fields of culture, of the scientific and technological progress, security and environmental protection;

- the principle of innovativeness and of the priority of intellectual activities, reflecting the view that the activities of dynamic management must be based on the innovations and the use of adequate intellectual resources, as well as that the development and activation of the dynamic management itself must be based on the promotion of innovations and on the development of the intellectual potential of society;

- the principle of universality, expressing the view that the ideas and tools of the dynamic management could and should be implemented in all areas of the life of modern society, including the public and business sectors, in all fields of the social, economic and political development, culture, art, scientific and technological progress, in many fields of the security and defence, in interaction with the environment, in other fields and areas;

-the principle of multi-leveling, expressing the view that the ideas and tools of dynamic management could and should be implemented in the life and activities of individuals, as well as in all spheres of the activities of various organizations, including of the activities at the local, regional, national, international and global level.

Obviously, the above-mentioned principles of the dynamic management can be considered as the most important: these principles cover all the essential and universal provisions relevant to the governance and management of the processes of economic growth, innovations and social and technological progress and breakthroughs. It is also evident that other additional principles of dynamic management can be formulated.

So it is obvious that the use and application of the ideas and tools of dynamic management could be understood as an essential prerequisite for the successful solution of many important problems of economic engineering. There are several key priorities that characterize the needs and perspectives of the application of the ideas and tools of dynamic management: among such priorities, the creation, dissemination, and implementation of innovations and high technologies may be mentioned as particularly important.

\section{The creation, dissemination, and implementation of innovations and high technologies: the "triple orientation" models and their application}

Undoubtedly, the creation, dissemination, and implementation of innovations and high technologies are key links in a variety of systems of the processes of economic growth, social and technological progress and other processes leading to the fundamental qualitative changes in all spheres of contemporary social and economic life. This means that the use and application of the ideas and tools of the dynamic management to activate and accelerate the processes of the creation, dissemination, and implementation of innovations and high technologies could and should be interpreted as an important priority of the practical activities, studies and scientific research on the economics engineering (Melnikas, 2011, 2013; Melnikas et al., 2018). In turn, the processes of the creation, dissemination, and implementation of innovations and high technologies could and should be interpreted as an important priority of the use and application of the ideas and tools of the dynamic management.

In general, the processes of the creation, dissemination, and implementation of innovations and high technologies, as a whole, could be defined as an area of the scientific cognition and practical activities where the links between the 
ideas, tools, and models of economics engineering and dynamic management are particularly prominent. It can be noted that the so-called "triple-orientation" models are particularly promising in the practice of the governance and management of the processes of the creation, dissemination, and implementation of innovations and high technologies: this fact also shows the essential links between the ideas, tools, and models of economics engineering and dynamic management.

The main idea of the "triple orientation" models and their application is that in each case, when it comes to activating and accelerating the processes of the creation, dissemination, and implementation of innovations and high technologies, the specific governance and management decisions and solutions covering three different but interrelated blocks should be prepared and realized in a complex way. These blocks of decisions and solutions are as follows:

- decisions and solutions for the initiation and creation of innovations and high technologies: priority for such decisions and solutions is to activate creativity and promote various synergies, in particular on the basis of multiculturalism, international cooperation, as well as the integration of different areas of the scientific and practical activities;

- decisions and solutions for the dissemination of innovations and high technologies: priority of such decisions and solutions is to activate international, interregional and intersectoral cooperation, to initiate and to develop the highly effective new value creation chains, to make widespread use of modern international marketing and public relations instruments, as well as various educational and other tools that should be adequate to meet the contemporary challenges of globalization, European integration and the knowledgebased society creation;

- decisions and solutions for the implementation of innovations and high technologies: priority for such decisions and solutions is to purposefully activate the investment processes, to create new organizations and organizational structures that should be adequate for the needs of the implementation of innovations and new technologies, to organize new enterprises and their networks, to develop the new productions and provisions of new services, to expand activities on large international and even global scale.

Each of these blocks includes multi-faceted strategic and other decisions and solutions oriented to the purposeful activation of the fundamental and applied research, design and other works, to the development of various forms and systems of the private-public partnership, to the effective promotion of investment processes, of various activities in human resource development and personnel management, to the intensive improvement of the production and service processes in all spheres of contemporary economy, as well as to the development of marketing activities and public relations, and extension of international cooperation.

The "triple orientation" models are characterized by the use of adequate decision support systems and algorithms, including the provision of tools to harmonize and balance the decisions and solutions belonging to different blocks.

"Triple orientation" models can be very useful in all cases where it is necessary to choose and initiate the most important promising directions for the creation, dissemination, and implementation of innovations and high technologies, as well as when it is necessary to prepare and justify responsible economic decisions and solutions for the economic growth and social and technological breakthroughs.

For example, in the case of Lithuania, these models could be successfully used and applied to create, disseminate and implement various innovations and high technologies in many areas of the social and economic life, as well as in many areas of the scientific and practical activities, including particularly important areas such as:

- various areas of fundamental sciences and practical activities, including the modern areas of physics, information technologies and digitization processes, electronics and telecommunications, mechanics and mechatronics technologies, biotechnologies and biomechanics, pharmacy, other areas;

- energetics, including various sectors of alternative energetics;

- industry and various sectors of industrial production, industrial engineering, and technologies, including engineering and technologies in various sectors of industry, multisectoral industry, and multifunctional industrial productions;

- various sectors of the service, including various specific business (financial, insurance, consulting and other services) and social-oriented service sectors (education, health care, and many other sectors), service engineering and technologies in various sectors,

- architecture, construction, and environmental engineering, including various fields of the science and practical activities in architecture and urbanization processes, building constructions and technologies, design, environmental protection and technologies, other fields;

- transport and logistics engineering, including engineering in various transport sectors, logistics engineering, aviation engineering, and technologies;

- various agricultural sectors, agricultural engineering, and technologies;

- various sectors of the entertainment and creative industries;

- defense and public security.

Of course, there are many other areas where the "triple orientation" models can be used, and these areas can be classified according to different characteristics and criteria. 

and technological breakthroughs

In all cases, it can be said that the "triple orientation" models are universal, the use and application of these models can lead to economic growth and technological progress and breakthroughs.

\section{Conclusions}

The conducted theoretical research makes it possible to formulate some substantive conclusions and recommendations:

1. Economics engineering involves many particularly new and promising directions and priorities in the scientific cognition, research, and academic studies, as well as in various areas of practical activities of the economic profile. An orientation to the dynamism of economic activities and the fundamental qualitative changes in economic life can be highlighted as the key exclusivity of economics engineering. The fundamental qualitative changes and orientations to these changes can be defined as the most important and exceptional feature of the science of economics engineering.

2. The role and importance of the science of economics engineering must be identified taking into account these key considerations: a) contemporary challenges and processes of globalization, European integration, and the knowledge-based society creation; b) the diversity and variety of the fields and directions of the processes of economic development and various technological, social and economic changes; c) the ever-increasing needs to activate and accelerate economic growth, innovations, social and technological progress, and breakthroughs. The modern science of economics engineering covers all fields of the contemporary social and economic life, includes many areas and directions of the scientific research and practical activities.

3. The problems, needs, and challenges of economic growth, scientific and technological progress and innovation activities must be a priority in the academic studies and in the scientific research on economics engineering. The scientific research on economics engineering should be based on the ideas of fundamental qualitative changes.

4. Most important practical activities in various fields of economics engineering should be based on the so-called principle of the creation of "a new quality". This principle reflects the focus on the synergies needed to respond successfully to the needs and challenges of economic growth, activation of innovation and technological breakthroughs.

5. Practical activities and scientific research in many fields of economics engineering must be based on the use and application of the ideas and tools of the so-called dynamic management. The use and application of these ideas and tools could be based on the principles of dynamism, humanistic attitudes and ethical and moral priorities, coherence and sustainability, rationality, efficiency and reasonableness, as well as on the principles of innovativeness and of the priority of intellectual activities, of universality, of multi-levelling: these principles, taken as a whole, reflect the wide range of opportunities for applying the ideas and tools of the dynamic management in a variety of cases when it comes to activating and accelerating the processes of economic growth, innovations and technological advancement and breakthroughs.

6. The creation, dissemination, and implementation of innovations and high technologies must be seen as a particularly promising and important area of the practical activities and scientific research on the economics engineering and dynamic management. The so-called "triple orientation" models and their application can be identified as a theoretical basis and precondition for initiating, developing and implementing effective economic and management decisions and solutions.

It can be noted that various practical activities and the complex scientific research, both on the processes of economic growth, innovations, technological advancement and breakthroughs, as well as on the dynamic management and application of its ideas and tools, are of exceptional importance and viability.

\section{References}

Aricly, D. (2008). Predictably irrational: the hidden forces that shape our decisions. NY: Harper Collins.

Baron, J. (2007). Thinking and deciding. UK: Cambridge University Press.

Binmore, K. (2009). Rational decisions. USA, ND: Princeton University Press.

Buede, D. M., \& Miller, W. D. (2016). The engineering design of systems: models and methods. NY: John Wiley and Sons.

Castells, M. (2000-2004). The information age, economy, society and culture (vol. 1. The Rise of the Network Society, 2000; vol. 2. The Power of Identity, 2004; vol. 3. End of Millenium, 2000). Oxford: Malden MA, Blackwell.

Chlivickas, E., \& Melnikas, B. (2016). Viešasis valdymas: aktualijos ir sprendimai globalizacijos ir žiniu visuomenès kūrimo sąlygomis. Vilnius: Technika. https://doi.org/10.3846/2364-M

Collier, P. (2018). The future of capitalism: facing the new anxieties. NY: Harper Collins.

Die Welt im Jahr 2035 gesehen von der CIA. Das Paradox des Fortschritts. (2017) Muenchen: Verlag C.H. Beck.

Endes, H. (2018). Adaptability through Dynamic Capabilities. How management can recognise opportunities and threats. Wiesbaden: Springer Gabler. https://doi.org/10.1007/978-3-658-20157-9

Harary, Y. N. (2016). Sapiens. Glausta žmonijos istorija. Vilnius: Kitos knygos.

Harary, Y. N. (2018). Homo Deus. Glausta rytojaus istorija. Vilnius: Kitos knygos.

Haskel, J., \& Westlake, S. (2018). Capitalism without capital: the rise of the intangible economy. New Jersey: Princeton University Press. https://doi.org/10.1515/9781400888320 
Melnikas, B. 2019. Contemporary issues in economics engineering: Economic growth, dynamic management, and technological breakthroughs

Hunt, S. D. (2000). A general theory of competition: resources, competences, productivity. Economic growth. London: Sage Publications.

Inamori, K. (2013). Amoeba management: the dynamic management system for rapid market response. USA: CRC Press, Taylor \& Francis Group.

In-Ho Kim, S. (2008). Dynamic management theory. Seoul: Hanyang University Press.

Johnson, D., \& Turner, C. (2010). International business: Themes and issues in the modern global economy. UK. London: Routledge. https://doi.org/10.4324/9780203861615

Loy, A., \& Aageson, T. (2018). Creative economy entrepreneurs: from startups to succes. How startups in the creative industries are transforming the global economy. Santa Fe: Creative Startups.

Marshall, T. (2018). Geografijos įkaitai. Dešimt žemélapiu, pasakančiu viska, kas lemia pasaulio politika. Vilnius: Tyto Alba.

Melnikas, B. (2011). Transformacijų visuomenè: ekonomika, kultūra, inovacijos, internacionalizavimo procesai. Vilnius: Technika.

Melnikas, B. (2013). Žiniomis grindžiamos visuomenès kūrimas: globalizacija, darni plètra, ekonominiai sprendimai. Vilnius: Vilniaus universiteto leidykla.

Melnikas, B. (2014). Tarptautinis verslas: inovacijos ir žiniu ekonomikos kūrimas. Vilnius: Technika.

Melnikas, B. (2018). The knowledge economy and the activation of scientific and technological progress: contemporary challenges. Ekonomika, 97(1), 7-23.

Melnikas, B., \& Reichelt, B. (2004). Wirtschaft und mentalitaet: tendenzen der EU-Osterweiterung. Leipzig, Leifim: Verlag.

Melnikas, B., Banelienè, R., Chlivickas, E., Jakubavičius, A., Lobanova, L. ir Žeimaitis, E. (2018). Intelektinis potencialas: glo balizacija ir žiniomis grindžiamos visuomenès kürimas. Vilnius: Technika. https://doi.org/10.20334/2018-032-M

Mody, A. (2018). Euro tragedy. A drama in nine acts. UK: Oxford University Press.

Neelankavil, J. P. (2015). International business research. London: M. E.Sharpe. https://doi.org/10.4324/9781315689876

Newnan, D., Lavelle, J., \& Eschenbach, T. (2017). Engineering economic analysis. UK: Oxford University Press.

Peterson, M. (2009). An introduction to decision theory. UK: Cambridge University Press. https://doi.org/10.1017/CBO9780511800917

Spetzler, C., Winter, H., \& Meyer, J. (2016). Decision quality: value creation from better business decision. NY: John Wiley and Sons. https://doi.org/10.1002/9781119176657

Steger, M. (2017). Globalization. A very short introduction. UK: Oxford University Press.

Teece, D. J. (2011). Dynamic capabilities and strategic management: organizing for innovation and growth. UK: Oxford University Press. 